\title{
An explanation of large-scale coal and gas outbursts in underground coal mines: the effect of low-permeability zones on abnormally abundant gas
}

\author{
F. H. An ${ }^{1,2}$ and Y. P. Cheng ${ }^{2,3}$ \\ ${ }^{1}$ College of Safety Science and Engineering, Henan Polytechnic University, Jiaozuo 454003, China \\ ${ }^{2}$ National Engineering Research Center for Coal \& Gas Control, Faculty of Safety Engineering, \\ China University of Mining \& Technology, Xuzhou 221116, China \\ ${ }^{3}$ State Key Laboratory of Coal Resources and Mine Safety, China University of Mining and Technology, \\ Xuzhou 221116, China
}

Correspondence to: Y. P. Cheng (fenghuazm009@163.com)

Received: 21 August 2013 - Published in Nat. Hazards Earth Syst. Sci. Discuss.: 12 September 2013

Revised: 29 May 2014 - Accepted: 5 July 2014 - Published: 21 August 2014

\begin{abstract}
Large-scale coal and gas outbursts pose a risk of fatal disasters in underground mines. Large-scale outbursts (outburst of coal and rock greater than $500 \mathrm{t}$ ) in recent years in China indicate that there is abundant gas in areas of outbursts containing large amounts of potential energy. The adequate sealing properties of the roof and floor of a coal seam are required for local abundant gas around the site of an outburst, but an annular low-permeability zone in a coal seam, which prevents the loss by gas migration through the coal seam itself, is also required. The distribution of coal gas with this annular zone of low permeability is described, and it is proposed that the annular zone of low permeability creates conditions for confining the coal gas. The effect of this lowpermeability zone on the gas distribution is analyzed after allowing for simplifications in the model. The results show that the permeability and length of the low-permeability zone have a great impact on the gas distribution, and the permeability is required to be several orders of magnitude less than that of normal coal and enough length is also in demand. A steep gradient of gas pressure in the low-permeability zone and the high-pressure gas in the abundant zone of gas can promote coal mass failure and coal wall deformation, thereby accelerating the coal and gas outburst. The high-pressure gas in abundant zone of gas will lead to a large-scale outburst if an outburst occurs.
\end{abstract}

\section{Introduction}

Coal and gas outbursts are a form of dynamic failure in which coal and gas are ejected violently by coal gas which is generated and stored in the coal. These outbursts are a concern for mine safety worldwide (Lama and Bodziony, 1998; Beamish and Crosdale, 1998). The largest of these outbursts, which may involve more than $500 \mathrm{t}$ of coal and rock, fill the working face or roadway with large volumes of coal, destroy roadway facilities by the sudden outflow of gas and even ruin an entire ventilation system. In such cases, even underground mine workers far from the site of the outburst may be affected, causing massive casualties.

In coal and gas outbursts prevention, regional gas control technologies, such as protecting seam exploitation, pressurerelief gas extraction, and strengthening gas extraction in advance, are the main technical approaches in China (Cheng and Yu, 2007). Protecting seam exploitation is the preferred approach for coal seam group. For efficient resource utilization and atmospheric environment protection, co-extraction of coal and methane has become a widely accepted idea in recent years (Guo et al., 2012). Underground boreholes and surface vertical wells are extensively utilized in gas drainage (Sang et al., 2010; Ying-Ke et al., 2011; Yang et al., 2011). Waterjet (Lu et al., 2011), hydraulic fracturing (Huang et al., 2011) and water infusion (Díaz Aguado and González Nicieza, 2007) are also used to reduce the risk of coal and gas outbursts. The development of coal and gas outbursts 


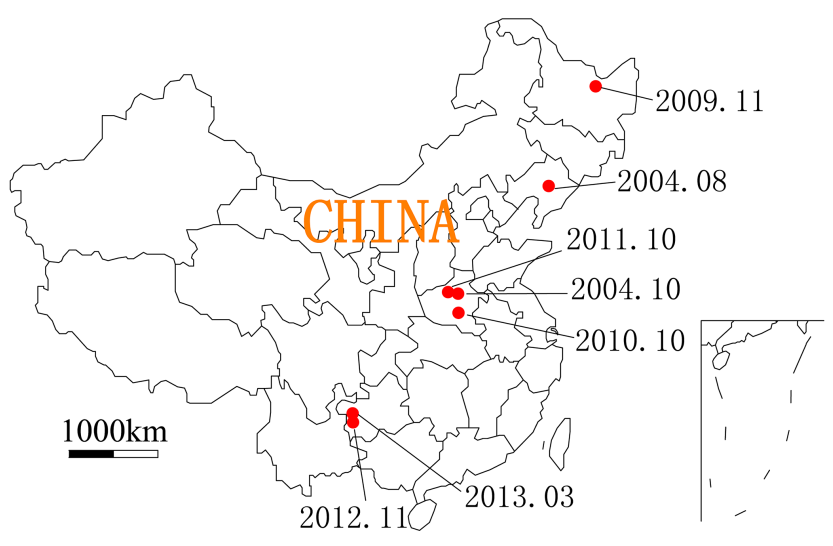

Figure 1. Locations of recent large-scale outbursts in China.

prevention benefits from the advance in outburst mechanism and the deeper understanding is still in demand.

Coal and gas outbursts are a complex process involving gas migration, coal failure and their interaction. Currently, a model synthesizing stress, coal gas, and coal physical and mechanical properties is widely used in qualitative descriptions of outburst conditions and processes. To quantitatively explain these outbursts, models describing coal mass failures caused by stress and coal gas have been developed after simplifying the physical processes involved (Paterson, 1986; Choi and Wold, 2001; Xu et al., 2006, 2011). Other related studies have analyzed the outburst conditions with regard to the tectonic conditions (Cao et al., 2001), spatial variability of permeability (Wold et al., 2008), and in situ stress characteristics (Han et al., 2012).

The understanding of the mechanism of large-scale outbursts is based on the above results, and further research into their particular conditions is lacking. These large-scale outbursts are pernicious due to the huge amount of energy released by gas flow, and the factors affecting the distribution of the energy before the outbursts warrant further study. Based on the large-scale outbursts in China over the last several years, their abnormal abundance in coal gas was analyzed, and the effects that low-permeability zones in coal seams have on the abnormal abundance of coal gas and largescale outbursts were studied.

\section{Abnormally abundant gas and geologic structures in large-scale outbursts}

\subsection{Abnormal abundance of coal gas in large-scale outbursts}

The study by Valliappan and Wohua (1999) showed that coal gas was primarily responsible for the energy released in the outbursts. As a result, the large-scale outbursts are accompanied by enormous amounts of outburst gas. The large-scale outbursts in China over the past few years are shown in Ta- ble 1, and the locations are shown in Fig. 1. The amount of outburst gas could be hundreds of thousands of cubic meters. The concentration increase could be detected by the gas sensors, and the amount of outburst gas is estimated by the quantity difference between the amount of coal gas in the airflow during the outburst and the amount in the normal times. In other words, hundreds of cubic meters of coal gas gush out per ton of outburst coal. This outflow of coal gas measures several to dozens of times the local gas content in nearby normal coal seam, and the coal gas content in the outburst area that is much more than the coal gas in other parts of the coal seam is abnormal. If these coal masses were mined normally, the gas outflow would be far less than the gas accompanying an outburst. Consider the example of the large-scale outburst in the Daping Coal Mine on 20 October 2004. The outburst of coal and rock measured $1894 \mathrm{t}$ (coal mass $1362 \mathrm{t}$ ), and the gas associated with the outburst measured approximately $250000 \mathrm{~m}^{3}$. The coal seam II 1 was being mined. The gas emissions in this coal mine measured $11.47 \mathrm{~m}^{3} \mathrm{t}^{-1}$ in 2003 . This measurement indicates that if the outburst coal were mined normally, the accompanying gas would measure $15622 \mathrm{~m}^{3}$, which is far below the amount of outburst gas. On the one hand, this amount indicates that the effect of stress release associated with the coal outburst is more pronounced than the stress release during normal mining. On the other hand, the amount demonstrates that the gas in and near the outburst area is more abundant than in other areas and could provide a large number of coal gas for the large-scale outbursts.

\subsection{Abnormal presence of coal gas and associated geologic structures}

Coal and gas outbursts tend to occur in zones affected by geological structures (Shepherd et al., 1981; Cao et al., 2001), and large-scale outbursts occur more often in or nearby the geological structures, as in the cases listed in Table 1 . In tectonic regions, the coal seam is deformed by the tectonic stress, creating conditions conducive to outbursts, including reduction in coal strength and high stress. At the same time, geological structures altered the conditions for generation, storing and migration of coal gas in coal measures. The distribution of coal gas in the same coal seam may vary greatly even at the same depth. The changes in load stress and fracture systems in coal masses by geological structures (Li et al., 2003; Han et al., 2012) are one factor controlling the migration of coal gas and the consequent distribution of coal gas (Pashin, 1998; Ayers, 2002; Yao et al., 2009; Groshong et al., 2009; Cai et al., 2011). These changes created conditions conducive to outbursts, particularly largescale outbursts backed by tremendous amounts of energy stored in the gas.

During work to control coal mine gas in the past years, it was found that the distribution of gas is nonuniform due to geological structure, and certain tectonic structures are 
Table 1. Recent large-scale outbursts in coal mines in China.

\begin{tabular}{|c|c|c|c|c|c|c|}
\hline Date & Location & $\begin{array}{r}\text { Quantity of } \\
\text { outburst } \\
\text { coal (t) }\end{array}$ & $\begin{array}{r}\text { Quantity of } \\
\text { outburst } \\
\text { gas }\left(10^{3} \mathrm{~m}^{3}\right)\end{array}$ & $\begin{array}{r}\text { Outburst gas per } \\
\text { ton of outburst } \\
\text { coal }\left(\mathrm{m}^{3} \mathrm{t}^{-1}\right)\end{array}$ & $\begin{array}{l}\text { Tectonic } \\
\text { conditions }\end{array}$ & $\begin{array}{l}\text { Relative gas emission } \\
\text { rate of the entire } \\
\text { mine }\left(\mathrm{m}^{3} \mathrm{t}^{-1}\right)^{*}\end{array}$ \\
\hline Aug 2004 & Hongling Coal Mine in Liaoning Province & 701 & 66.2 & 94.5 & Fault & $39.3(2003)$ \\
\hline Oct 2004 & Daping Coal Mine in Zhengzhou City & 1362 & 250 & 183.6 & Reverse fault & $11.47(2003)$ \\
\hline Nov 2009 & Xinxing Coal Mine in Heilongjiang Province & 1697 & 166.3 & 98.0 & $\begin{array}{l}\text { Normal fault, } \\
\text { igneous rock } \\
\text { intrusion }\end{array}$ & $7.98(2009)$ \\
\hline Oct 2010 & $\begin{array}{l}\text { The Fourth Coal Mine of Pingyu Coal and } \\
\text { Electricity in Henan Province }\end{array}$ & 2547 & 150 & 58.9 & $\begin{array}{l}\text { Coal seam thick- } \\
\text { ness increase }\end{array}$ & $6.03(2010)$ \\
\hline Oct 2011 & Jiulishan Coal Mine in Henan Province & 2893 & 291.1 & 100.6 & Reverse fault & $24.17(2010)$ \\
\hline Nov 2012 & Xiangshui Coal Mine in Guizhou Province & 490 & 45 & 91.8 & $\begin{array}{l}\text { Coal seam thick- } \\
\text { ness increase }\end{array}$ & \\
\hline Mar 2013 & Machang Coal Mine in Guizhou Province & 2051 & 352 & 171.6 & Fold and fault & \\
\hline
\end{tabular}

* The year in parentheses is that in which the emission rate was measured.

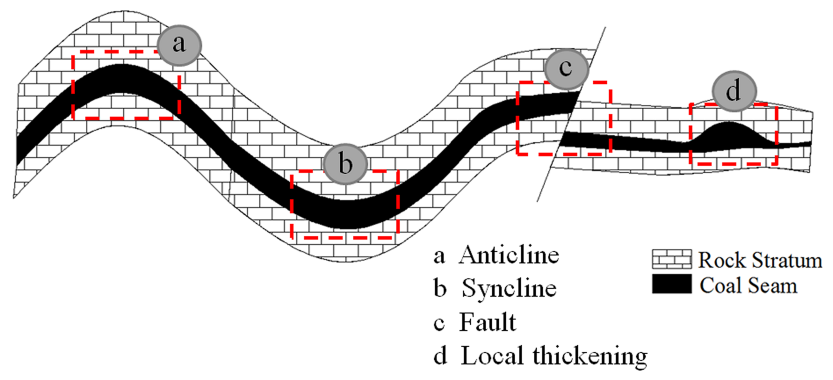

Figure 2. Abundant zones of coal gas in some geologic structures.

beneficial to the storage of coal gas. The outbursts nearly always occurred in long, narrow "outburst zones" along the intensely deformed zones of geological structures (Cao et al., 2001), and the research focus in the paper is put on the minescale geological structures or smaller ones. In coal measures in a syncline or anticline, the amount of coal gas is relatively high in the axial zone, when the roof and floor of the coal seam display good sealing properties, as shown in Fig. 2a and b. Fault sealing constitutes a low-permeability boundary and blocks the migration of coal gas, and abnormally abundant gases often develop next to these fault contacts, as shown in Fig. 2c. In cases in which the coal seam thickness is altered by tectogenesis, a coal seam thickens in a local area, producing a coal package. The surrounding area of the coal seam thins, and the migration of coal gas becomes more difficult, leading to the sealing of coal gas in the package, as shown in Fig. 2d. These areas are also associated with large-scale outbursts, as listed in Table 1.

\section{Modeling and analysis of abundant gas preservation}

\subsection{Preservation conditions of abundant gas and annular zone of low permeability}

Enormous amounts of outburst gas indicate that abnormally abundant coal gas has been stored in the outburst area, which is indicative of the large amount of energy required for a large-scale outburst. In addition to the good sealing properties of roof, the area surrounding the abundant gas zone in the coal seam should have low permeability to impede the loss of high-pressure gas through the coal seam itself. Such a zone of concentrated coal gas held within an annular zone of low permeability is shown in Fig. 3, and the spatial scale is about mine scale. This zone of low permeability confines the concentrated coal gas zone and maintains the gas content at a level higher than that of normal areas of the coal seam throughout a certain span of time. In areas of tectonism, the alteration of the fracture system in the coal seam reduces the permeability greatly ( $\mathrm{Li}$ et al., 2003), and the high tectonic stress can decrease the permeability greatly as well (Somerton et al., 1975; Jasinge et al., 2011). A lowpermeability zone can develop and affect the coal gas distribution, i.e., the preservation conditions resulting in abnormal concentrations of coal gas and the consequent energy for large-scale outbursts.

To analyze the effect that low-permeability zones in coal seams exert in coal gas preservation, it was assumed that the coal gas migration involves neither continuing gas generation nor boundary changes by geological structure that might affect gas migration. With their effective sealing properties, the roof and floor of the coal seam are regarded as non-flow boundaries. Given the above simplifications, a concentration of coal gas within an annular zone of low permeability can be 


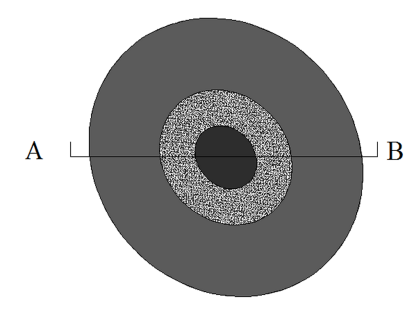

A

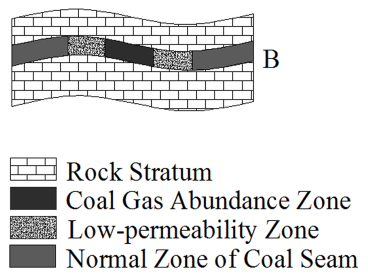

Figure 3. Annular low-permeability zone in coal seam.

simplified as a one-dimensional flow model involving porous media.

The continuity equation of gas migration in the coal seam can be expressed as

$\frac{\partial(m)}{\partial t}-\nabla \cdot\left(\rho_{\mathrm{g}} v_{\mathrm{g}}\right)=0$,

where $m$ is the coal gas content $\left(\mathrm{kg} \mathrm{m}^{-3}\right), \rho_{\mathrm{g}}$ is the coal gas density $\left(\mathrm{kg} \mathrm{m}^{-3}\right), v_{\mathrm{g}}$ is the seepage velocity $\left(\mathrm{m} \mathrm{s}^{-1}\right)$ and $t$ is time (s). The coal gas consists of adsorbed gas and free gas, and the content can be calculated using

$m=\left(\frac{V_{L} p}{p+p_{L}}+\frac{\phi p}{\rho_{\mathrm{c}} p_{0}}\right) \cdot \frac{\rho_{\mathrm{c}} M}{V_{M}}$,

where $V_{L}$ is the maximum adsorption capacity of the coal mass $\left(\mathrm{m}^{3} \mathrm{t}^{-1}\right), p_{L}$ is the Langmuir pressure representing the increasing trend of the adsorption volume with the gas pressure $\left(\mathrm{MPa}^{-1}\right), p$ is the coal gas pressure $(\mathrm{MPa}), \rho_{\mathrm{c}}$ is the bulk density of coal $\left(\mathrm{kg} \mathrm{m}^{-3}\right), \phi$ represents the porosity of coal and $p_{0}$ is the atmospheric pressure $0.10325 \mathrm{MPa}$. The coal gas density can be calculated using the ideal gas equation

$\rho_{\mathrm{g}}=\frac{p M}{R T}$,

where $M$ is the molar mass of the gas $\left(16 \mathrm{~g} \mathrm{~mol}^{-1}\right.$ for methane), $R$ is the gas constant $8.314 \mathrm{~J} /\left(\mathrm{mol} \mathrm{K}^{-1}\right)$ and $T$ is the coal seam temperature $(\mathrm{K})$.

The coal gas migration in the coal seam is flow that obeys Darcy's law, given as

$v_{\mathrm{g}}=-\frac{k}{\eta_{\mathrm{g}}} \nabla p$,

where $\eta_{\mathrm{g}}$ is the coefficient of kinetic viscosity $\left(1.08 \times 10^{-5} \mathrm{pas}^{-1}\right.$ for methane) and $k$ is the permeability of the coal seam $\left(\mathrm{m}^{2}\right)$.

The model for analyzing the preservation effect on coal gas is a one-dimensional flow model with a low-permeability zone, as shown in Fig. 4. The total length is $2500 \mathrm{~m}$, and zone $\mathrm{I}$ is $100 \mathrm{~m}$ wide. The permeability of zones I and II are those of a normal coal seam, and zone II is a low-permeability

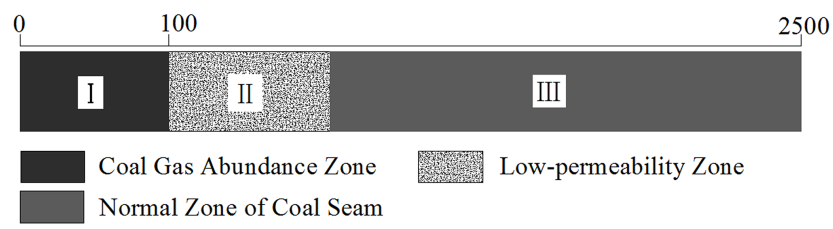

Figure 4. One-dimensional flow model of coal gas with a lowpermeability zone.

Table 2. Parameters of the flow model.

\begin{tabular}{lrl}
\hline Parameter & Value & Unit \\
\hline Maximum adsorption capacity of coal mass $V_{L}$ & 20 & $\mathrm{~m}^{3} \mathrm{t}^{-1}$ \\
Langmuir pressure $P_{L}$ & 1 & $\mathrm{MPa}^{-1}$ \\
Bulk density of coal $\rho_{\mathrm{c}}$ & 1.35 & $\mathrm{t} \mathrm{m}^{-3}$ \\
Porosity of coal $\varphi$ & 0.06 & - \\
Coal seam temperature $T$ & 303 & $\mathrm{~K}$ \\
Permeability of coal seam $k$ & 0.025 & $\mathrm{mD}$ \\
\hline
\end{tabular}

zone. The parameters of the model are shown in Table 2. The initial gas pressure in the coal seam is $2.5 \mathrm{MPa}$. The right boundary is a low-pressure boundary, and the pressure is atmospheric. Because the coal gas in the zone inside the annular low-permeability zone is limited, the left boundary is considered a non-flow boundary.

\subsection{Results and analysis}

Based on a length of zone II of $200 \mathrm{~m}$, cases in which the permeability was $10,1,0.1$ and $0.01 \%$ of the permeability of a normal coal seam were analyzed. After various times of gas migration, the gas pressure distributions from the left boundary are shown in Fig. 5. From these calculations, we found that the gas lost through the coal seam is reduced by the low-permeability zone. When the permeability of zone II was smaller than $0.1 \%$ of the permeability of the normal coal seam, the gas in zone I can still maintain the initial gas pressure $(2.5 \mathrm{MPa})$ even after $10^{4}$ years. The coal gas in zone I can maintain high pressure after a long period of gas migration. In the numerical example the gas pressure in zone I with coordinate less than $100 \mathrm{~m}$, which is inside the low-permeability zone with $0.01 \%$, can be $1.69 \mathrm{MPa}$ after $10^{6}$ years of gas migration, much higher than $0.15 \mathrm{MPa}$ in the case without low-permeability zone. Due to the permeability reduction of the low-permeability zone, the abundant gas zone can maintain higher gas pressure, resulting in an abundant zone of gas. And the gas pressure gradient steepens as well. The concentration of coal gas outside the zone is less than that of a normal coal seam due to insufficient replenishment from the low-permeability zone. The gas pressure in the case of $0.01 \%$ permeability in zone II was $1.38 \mathrm{MPa}$ at position of $300 \mathrm{~m}$ after $10^{4}$ years of gas migration, lower than $1.50 \mathrm{MPa}$ in the case without low-permeability zone. But this effect would vanish with time. When the coal seam contains 

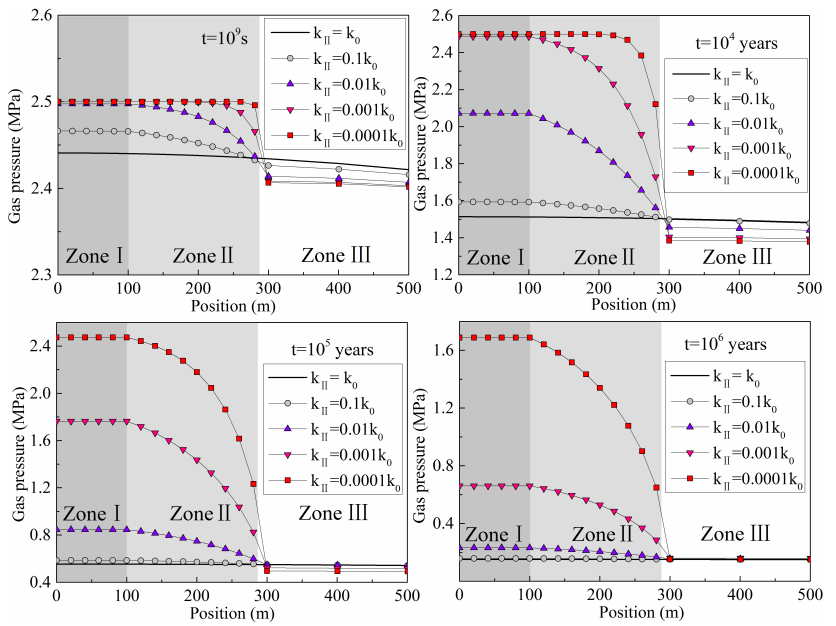

Figure 5. Gas distributions with various permeability properties of the low-permeability zone.
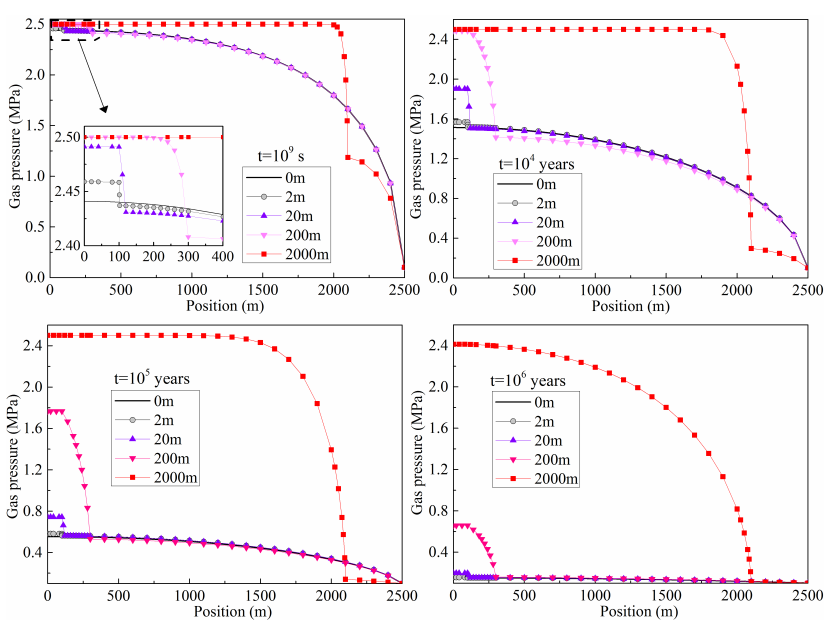

Figure 6. Gas distribution with various lengths of the lowpermeability zone with permeability $0.1 \%$ of the normal coal seam permeability.

no low-permeability zone or its permeability is merely several times less than the normal permeability, the coal gas will escape though low-pressure boundaries around the coal seam. No local concentration of gas can develop, even though the roof and floor strata exhibit good sealing properties.

The effect of the width of the low-permeability zone in cases where the permeability of the low-permeability zone is $0.1 \%$ of the normal coal seam permeability was studied. The gas pressure distributions are shown in Fig. 6, in which the length of the low-permeability zone was 2, 20, 200 and $2000 \mathrm{~m}$. The results demonstrate that the length of the lowpermeability zone has an important effect on gas preservation. In the example, when the length of the low-permeability zone was $2000 \mathrm{~m}$, the gas pressure in the zone with coordinate less than $100 \mathrm{~m}$ can be still more than $2.4 \mathrm{MPa}$ after $10^{5}$

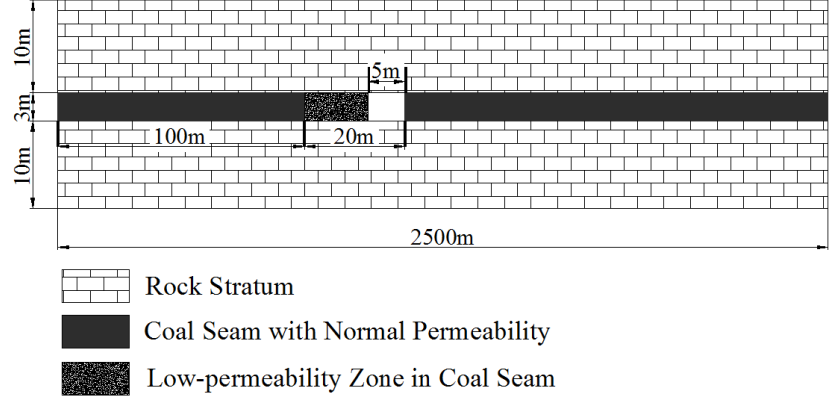

Figure 7. Geometry and boundary conditions.

or $10^{6}$ years, much higher than other cases. The larger lowpermeability zone promotes the confinement of the coal gas, and this effect becomes more pronounced with time. A narrower low-permeability zone may create a larger gas pressure gradient.

Based on the above analysis, we conclude that when a lowpermeability zone is present in a coal seam, a high gas pressure gradient is present in this zone, and the coal gas can be held in the inner zone, thus creating a local abundant zone of gas during the long time gas migration. In this process, to maintain the coal gas in the inner zone, the permeability of the low-permeability zone is required to be several orders of magnitude less than that of normal coal and the length is also in demand.

\section{Effect of low-permeability zone on the likelihood of outburst}

\subsection{Model and conditions}

A higher gas pressure gradient increases the likelihood of an outburst. A high gas pressure gradient and high gas concentrations tend to be associated with low-permeability zones. In this section of the paper, a model for analyzing the effect that low-permeability zones have on producing outbursts is described.

Considering the effect of coal gas pressure on the stress state, the effective stress in the coal mass can be expressed as

$\sigma_{i j}=\sigma_{i j}^{\prime}-\delta_{i j} \alpha p$,

where $\sigma_{i j}$ is stress, $\sigma_{i j}^{\prime}$ is the effective stress, $\delta_{i j}$ is the Kronecker delta function which is 1 when $i=j$, and $\alpha$ is the pore pressure coefficient.

In this model, the coal mass is regarded as an elasticplastic medium, following the Mohr-Coulomb matching Drucker-Prager yield criterion

$F=\alpha_{\mathrm{DP}} I_{1}+k_{\mathrm{DP}}-\sqrt{J_{2}}$,

where $I_{1}$ is the first stress invariant, $J_{2}$ is the second deviator stress invariant, and $\alpha_{\mathrm{DP}}$ and $k_{\mathrm{DP}}$ are identified by the 
Table 3. Parameters used in the model.

\begin{tabular}{lrl}
\hline Parameter & Value & Unit \\
\hline Pore pressure coefficient $\alpha$ & 0.75 & 1 \\
Cohesion of coal $C_{\mathrm{c}}$ & 1.5 & $\mathrm{MPa}$ \\
Friction angle of coal $\psi_{\mathrm{c}}$ & 35 & $\circ$ \\
Poisson ratio of coal $v_{\mathrm{c}}$ & 0.4 & 1 \\
Elastic modulus of coal $E_{\mathrm{c}}$ & 2.5 & $\mathrm{GPa}$ \\
Bulk density of rock $\rho_{\mathrm{r}}$ & 2.5 & $\mathrm{t} \mathrm{m}^{-3}$ \\
Cohesion of rock $C_{\mathrm{r}}$ & 20 & $\mathrm{MPa}$ \\
Friction angle of rock $\psi_{\mathrm{r}}$ & 40 & $\circ$ \\
Poisson ratio of rock $v_{\mathrm{r}}$ & 0.3 & 1 \\
Elastic modulus of coal $E_{\mathrm{r}}$ & 30 & $\mathrm{GPa}$ \\
\hline
\end{tabular}

cohesion $C$ and friction angle $\varphi$ as

$\alpha_{\mathrm{DP}}=\frac{\sin \varphi}{\sqrt{3} \sqrt{3+\sin ^{2} \varphi}}$,

$k_{\mathrm{DP}}=\frac{3 C \cos \varphi}{\sqrt{3} \sqrt{3+\sin ^{2} \varphi}}$.

The mechanical parameters in the model are listed in Table 3 , and the geometry and boundary conditions are shown in Fig. 7. The roof and floor strata are impermeable, and the roof is loaded by $400 \mathrm{~m}$ of overlying rock. The permeability values of the low-permeability zone are $10,1,0.1$ and $0.01 \%$ of normal coal seam permeability, and the low-permeability zone is $20 \mathrm{~m}$ long. The initial gas pressure is $2.5 \mathrm{MPa}$, and the migration conditions are the same as those in the above analysis of the effect of the low-permeability zone on gas migration. After the coal gas migration, for $10^{5}$ years in this study, the gas distribution is different. A coal mass $5 \mathrm{~m}$ long in the front of low-permeability zone is excavated, and the plastic development in front of coal wall and the deformation of coal wall are analyzed.

\subsection{Results and analysis}

After $10^{5}$ years of gas migration, the gas pressure distributions in the coal seam with various low-permeability zones progressing away from the left boundary are shown in Fig. 8. The gas pressure outside the low-permeability zone is close to that of the normal coal seam and is progressively higher in the low-permeability zone. The gas pressure at position $100 \mathrm{~m}$ was $1.47,0.74,0.59,0.57,0.57 \mathrm{MPa}$ as the permeability reduction of low-permeability zone. Then, the $5 \mathrm{~m}$ long coal mass in the front of low-permeability zone, shown by the gray area in Fig. 8, is excavated. The effect of the concentrated gas and the pressure gradient with the various lowpermeability zones on the deformation and failure of the coal mass is studied.

The area of plastic failure and maximum plastic strain of the coal mass in front of the coal wall are more severe

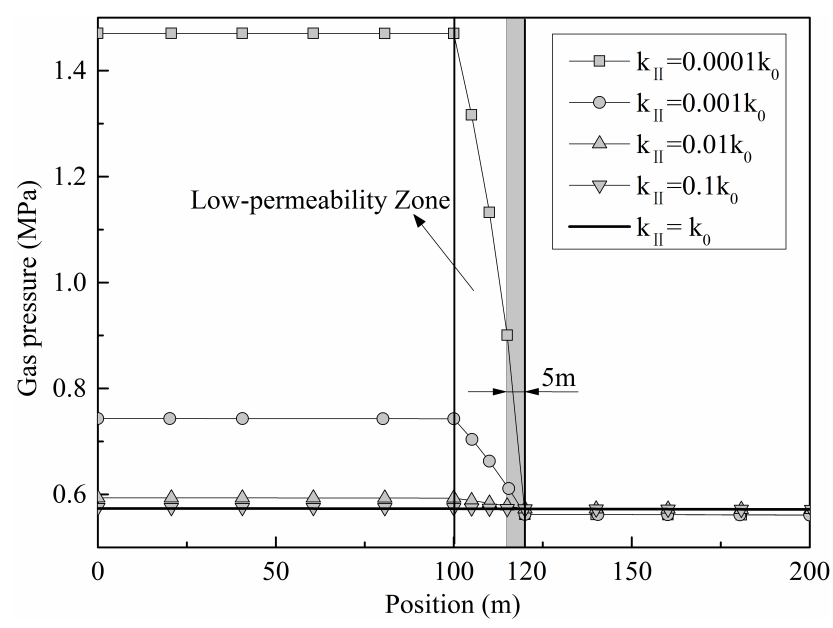

Figure 8. Gas distribution after $10^{5}$ years of gas migration.

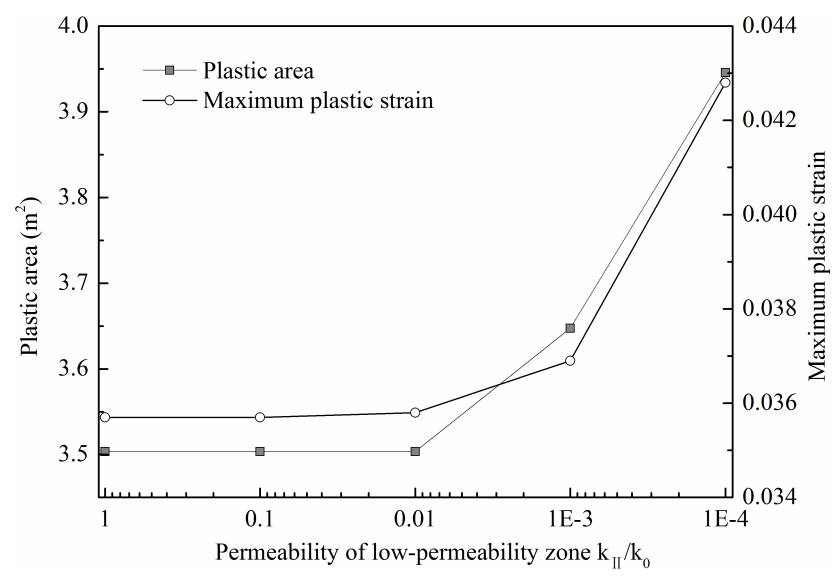

Figure 9. Plastic development in front of coal wall.

with a low-permeability zone and become more pronounced with the permeability decrease in the low-permeability zone, as shown in Fig. 9. The coal wall in front of the lowpermeability zone displays greater deformation as well. As shown in Fig. 10, the maximum strain and displacement of the coal wall are progressively larger with the progressive decrease in permeability in the low-permeability zone. These effects are especially pronounced when the permeability of the low-permeability zone is very low. These findings demonstrate that with greater pressure gradient the lowpermeability zone has a significant impact on the likelihood of outbursts.

The failure of the coal mass and deformation of the coal wall are promoted by the high gas content and gas pressure gradient created by the low-permeability zone, which initiates and accelerates the outbursts. The high energy of the coal gas in the abundant zone of gas provides the enormous amounts of energy released in outbursts in general and large-scale outbursts in particular. Even where a coal seam contains little gas and the outburst danger is generally 


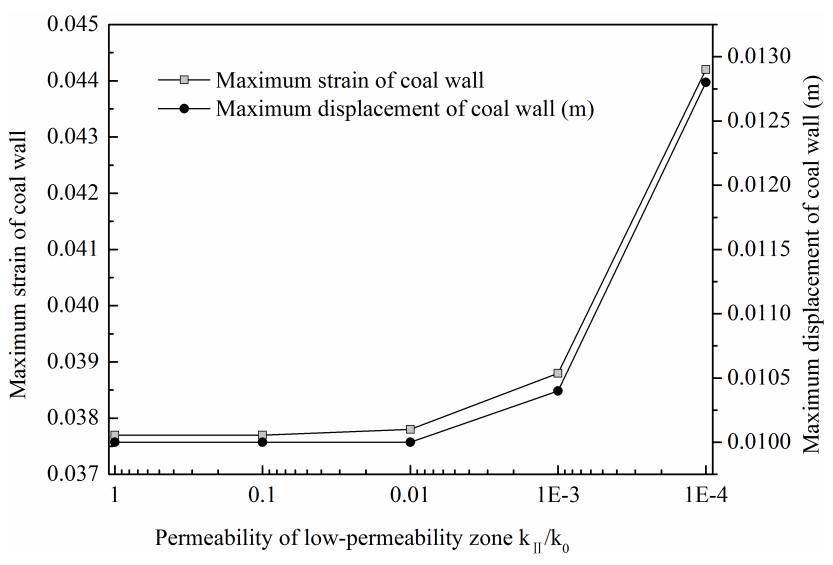

Figure 10. Deformation of coal wall.

low, local large-scale outbursts at that same depth are possible due to the gas contained within low-permeability zones. Hence, when the abnormal abundance of coal gas is found, the low-permeability zone may follow. From contacting the low-permeability zone, more drainage measures are necessary to eliminate the outburst danger. More prevention measures are required in such areas than in normal coal seams.

\section{Conclusions}

The analysis of large-scale outbursts in recent years in China indicates that there are abundant zones of gas near outburst locations. Large-scale outbursts are common in areas affected by geological structures, which reduce the permeability of coal through deforming fracture systems and the high stress state. The resulting lower permeability zones can alter the distribution of gas, and form zones of abundant gas over long periods of time associated with gas migration.

Besides good sealing properties of the roof and floor rocks, the local abundant gas at the site of an outburst requires a low-permeability zone in the coal seam to prevent the migration and loss of gas through the coal seam itself. The distribution of abundant coal gas inside an annular zone of low permeability is proposed, and the effect of the low-permeability zone on gas distribution is analyzed based on simplifications. The results indicate that the gas inside a low-permeability zone can be contained over a long span of time, leading to local pockets of concentrated gas. Without the effect of low-permeability zones, the high-pressure gas would be lost across the low-pressure boundaries of coal seam. In the long time of gas migration, to maintain the coal gas in the inner zone, the permeability of the low-permeability zone is required to be several orders of magnitude less than that of normal coal and enough length is also in demand.

The steep gradient of gas pressures in a low-permeability zone and high-pressure gas in the abundant zone of gas may create conditions conducive to coal and gas outbursts even if it is safe in the surrounding area. When excavation proceeds into the low-permeability zone, the failure of the coal mass and deformation of the coal wall increase and become more pronounced with the permeability reduction of the low-permeability zone. Where high-pressure gas is confined within a low-permeability zone, large amounts of energy in the zone of abnormally abundant gas may lead to a large-scale outburst. Therefore, from contacting the lowpermeability zone, more drainage measures are necessary to eliminate the outburst danger.

Acknowledgements. This work is financially supported by the National Foundation of China (no. 51074160), the National Basic Research Program of China (973 Program, no. 2011CB201204), the National Science Foundation of China (no. 51004106, no. 41202118, no. 51304188) and China Postdoctoral Science Foundation (no. 2014t70561).

Edited by: F. Guzzetti

Reviewed by: two anonymous referees

\section{References}

Ayers, W. B.: Coalbed gas systems, resources, and production and a review of contrasting cases from the San Juan and Powder River basins, AAPG Bull., 86, 1853-1890, 2002.

Beamish, B. and Crosdale, P. J.: Instantaneous outbursts in underground coal mines: an overview and association with coal type, Int. J. Coal Geol., 35, 27-55, 1998.

Cai, Y., Liu, D., Yao, Y., Li, J., and Qiu, Y.: Geological controls on prediction of coalbed methane of No. 3 coal seam in Southern Qinshui Basin, North China, Int. J. Coal Geol., 88, 101-112, 2011.

Cao, Y., He, D., and Glick, D. C.: Coal and gas outbursts in footwalls of reverse faults, Int. J. Coal Geol., 48, 47-63, 2001.

Cheng, Y. and Yu, Q.: Development of Regional Gas Control Technology for Chinese Coal mines, J. Mining Safety Eng., 24, 383390, 2007.

Choi, S. and Wold, M.: A mechanistic study of coal and gas outbursts, DC Rocks 2001, The 38th US Symposium on Rock Mechanics (USRMS), January, 2001.

Díaz Aguado, M. B. and González Nicieza, C.: Control and prevention of gas outbursts in coal mines, Riosa-Olloniego coalfield, Spain, Int. J. Coal Geol., 69, 253-266, 2007.

Groshong, R. H. Jr., Pashin, J. C., and McIntyre, M. R.: Structural controls on fractured coal reservoirs in the southern Appalachian Black Warrior foreland basin, J. Struct. Geol., 31, 874886, 2009.

Guo, H., Yuan, L., Shen, B., Qu, Q., and Xue, J.: Mining-induced strata stress changes, fractures and gas flow dynamics in multiseam longwall mining, Int. J. Rock Mechan. Mining Sci., 54, 129-139, 2012.

Han, J., Zhang, H., Li, S., and Song, W.: The characteristic of in situ stress in outburst area of China, Safety Sci., 50, 878-884, 2012.

Huang, B., Liu, C., Fu, J., and Guan, H.: Hydraulic fracturing after water pressure control blasting for increased fracturing, Int. J. Rock Mechan. Mining Sci., 48, 976-983, 2011. 
Jasinge, D., Ranjith, P., and Choi, S.-K.: Effects of effective stress changes on permeability of latrobe valley brown coal, Fuel, 90, 1292-1300, 2011.

Lama, R. and Bodziony, J.: Management of outburst in underground coal mines, Int. J. Coal Geol., 35, 83-115, 1998.

Li, H., Ogawa, Y., and Shimada, S.: Mechanism of methane flow through sheared coals and its role on methane recovery, Fuel, 82, 1271-1279, 2003.

Liu, Y., Zhou, F., Liu, L., Liu, C., and Hu, S.: An experimental and numerical investigation on the deformation of overlying coal seams above double-seam extraction for controlling coal mine methane emissions, Int. J. Coal Geol., 87, 139-149, 2011.

Lu, T., Zhao, Z., and Hu, H.: Improving the gate road development rate and reducing outburst occurrences using the waterjet technique in high gas content outburst-prone soft coal seam, Int. J. Rock Mechan. Mining Sci., 48, 1271-1282, 2011.

Pashin, J. C.: Stratigraphy and structure of coalbed methane reservoirs in the United States: an overview, Int. J. Coal Geol., 35, 209-240, 1998.

Paterson, L.: A model for outbursts in coal, Int. J. Rock Mechan. Mining Sci. Geomechan. Abstracts, 23, 327-332, 1986.

Sang, S., Xu, H., Fang, L., Li, G., and Huang, H.: Stress relief coalbed methane drainage by surface vertical wells in China, Int. J. Coal Geol., 82, 196-203, 2010.

Shepherd, J., Rixon, L., and Griffiths, L.: Outbursts and geological structures in coal mines: a review, Int. J. Rock Mechan. Mining Sci. Geomechan. Abstracts, 18, 267-283, 1981.
Somerton, W. H., Söylemezoḡlu, I., and Dudley, R.: Effect of stress on permeability of coal, Int. J. Rock Mechani. Mining Sci. Geomechan. Abstracts, 12, 129-145, 1975.

Valliappan, S. and Wohua, Z.: Role of gas energy during coal outbursts, Int. J. Numer. Methods Eng., 44, 875-895, 1999.

Wold, M., Connell, L., and Choi, S.: The role of spatial variability in coal seam parameters on gas outburst behaviour during coal mining, Int. J. Coal Geol., 75, 1-14, 2008.

Xu, T., Tang, C., Yang, T., Zhu, W., and Liu, J.: Numerical investigation of coal and gas outbursts in underground collieries, Int. J. Rock Mechani. Mining Sci., 43, 905-919, 2006.

Xue, S., Wang, Y., Xie, J., and Wang, G.: A coupled approach to simulate initiation of outbursts of coal and gas-model development, Int. J. Coal Geol., 86, 222-230, 2011.

Yang, W., Lin, B.-Q., Qu, Y.-A., Zhao, S., Zhai, C., Jia, L.-L., and Zhao, W.-Q.: Mechanism of strata deformation under protective seam and its application for relieved methane control, Int. J. Coal Geol., 85, 300-306, 2011.

Yao, Y., Liu, D., Tang, D., Tang, S., Che, Y., and Huang, W.: Preliminary evaluation of the coalbed methane production potential and its geological controls in the Weibei Coalfield, Southeastern Ordos Basin, China, Int. J. Coal Geol., 78, 1-15, 2009. 